\title{
Design of a Muffler \& Effect of Resonator length for 3 Cylinder SI Engine
}

\author{
Shubham Pal ${ }^{1}$, Tejpreet Singh Golan ${ }^{2}$, Vinod $\mathrm{Kumar}^{3}$, Virag Jain ${ }^{4}$, Nilesh \\ Ramdas $^{5}$, O. P. Sharma ${ }^{6}$ \\ 1, 2, 3, 4, 5, 6 (Department of Mechanical Engineering, Inderprastha Engineering College, Ghaziabad, Uttar \\ Pradesh, India)
}

\begin{abstract}
An IC engine is a major source of noise pollution, where exhaust noise play major contribution. That is why the reduction of exhaust noise from engines is an important issue. A muffler in the exhaust pipe is used for reducing noise. Muffler requires specific design considering various noise parameters. In this the tunable resonator is used whose length can be varied by using a piston that can be set at different positions. Noise level is also measured at the different positions of resonator to check the effect of variation of length of silencer that shows the smaller the resonator size better is insertion loss. A muffler for stationary petrol engine (engine test rig) has been designed. Sound level is measured before and muffler installation at different position of resonator piston \& the effect of resonator length is studied.
\end{abstract}

Keywords: - Muffler, Insertion loss, Resonator, Exhaust noise

\section{INTRODUCTION}

Silencer is also termed as muffler. It is used for reducing the noise emitted by exhaust of an internal combustion engine, which is a major source of noise pollution. It becomes a more vital concern when used in residential areas or areas where noise creates hazard. Generally, noise level of more than $80-90 \mathrm{~dB}$ is injurious for human being. The main sources of noise in an engine are divided in two parts, first is the exhaust noise and second is the noise produced due to friction of various parts of the engine. The engine exhaust noise is the most dominant. To reduce this noise, the most effective way of using a muffler in the engines. The level of noise reduction depends upon the design, construction and the working procedure of mufflers. If a car running without a muffler then the noise level is unbearable[1]. The most of the advances in the acoustic filters and exhaust mufflers came out in last four decades. Hence good design of the muffler should give the best noise reduction and offer optimum backpressure for the engine[2]. Backpressure is the extra static pressure exerted by muffler on the engine through the restriction in the flow of exhaust gases. The insertion loss is defined as the difference in the acoustic power radiated without and with the muffler fitted.

\section{A. Types of silencers}

Generally there are two types of mufflers.

\section{Absorptive Mufflers}

The first type, shown in Figure 1, is frequently chosen because of its low cost and because it causes a lower back pressure. It uses the absorption to reduce the sound energy. Sound waves are reduced as their energy is converted into heat in the absorptive material. In the absorptive muffler the exhaust noise is passed from straight pipe which are perforated and absorptive materials like glass fibers, steel wool are used to absorb the noise as shown in Figure 1.

In Absorptive silencer design, noise energy is effectively absorbed by various types of fibrous packing materials; the resulting viscous friction dissipates the sound energy as small amounts of heat. Better performance at lower frequency is obtained as the thickness of the absorbing material is increased[1].

\section{Reactive Mufflers}

The second type, shown in Figure 2, provides more attenuation referred as reactive muffler. The engine noise is reduced by the passing the exhaust from the various chambers in case of a reactive muffler as shown in Figure 2. It generally consists of a series of a resonating and expansion chambers that are designed to reduce sound pressure level at certain frequencies. These are widely used in car exhaust systems where exhaust gas flow and hence noise emission varies with time. Absorptive mufflers reduces the less noise but they have an advantage of lesser backpressure comparative to reactive mufflers[2]. 


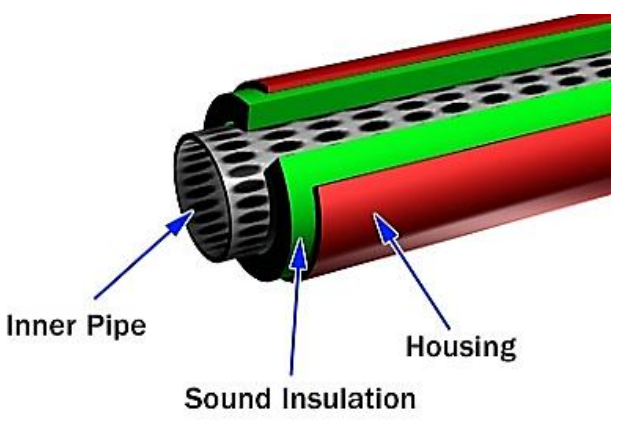

Figure 1 Absorptive Muffler[2]

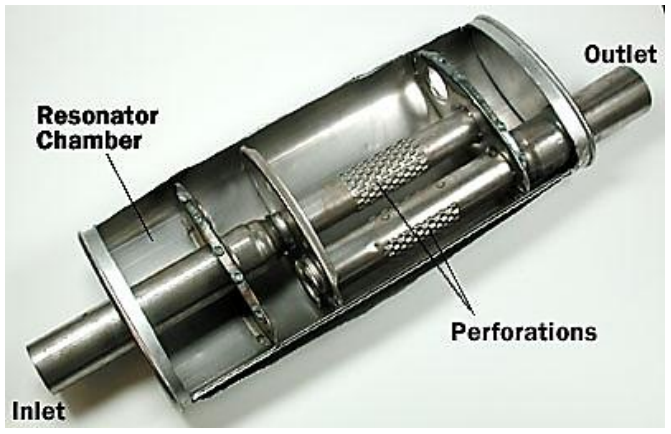

Figure 2 Reactive Muffler[2]

\section{LITERATURE REVIEW}

The performance of an exhaust system is assessed by a different factors; the most important factors are backpressure and the insertion loss of the system. High backpressure in an exhaust system affects the performance of the engine, decreasing power and increasing fuel consumption, and hence emissions.

Exhaust noise can be classified into two categories: pulsating noise from the engine, and flow noise from high speed exhaust gasses flowing though and exiting the exhaust system. Pulsating noise is generated when exhaust gases at high pressure are released from the engine cylinders through the exhaust valves. Flow noise is created by exhaust gas flow eddying, oscillating and impacting inside the exhaust system as well as jet noise as the flow exits the system[3].

There are five different design criterion of mufflers design. These are Acoustical Criterion, Aero dynamical Criterion, Mechanical Criterion, Geometrical Criterion and Economical Criterion. The acoustical criterion which specifies the minimum noise reduction required from the muffler as a function of frequency. Aero dynamical Criterion specifies the maximum acceptable pressure drop through the muffler at given temperature and mass flow. The Mechanical criterion specifies the materials from which the muffler is fabricated or designed. So that it is durable and requires less maintenance. Geometrical Criterion specifies the maximum allowable value and restriction on shape. The Economical Criterion is vital in the market place. A muffler must be inexpensive as possible while designing initial cost as well as operating cost must be considered[4].

Now-a-days the mufflers are analyzed for the flow considerations and acoustical considerations with the help of CFD (Computational Fluid Dynamics). But this requires higher level of computer hardware and more efficient computer system to compute the complex calculations. Some literatures on CFD are reviewed here.

The various dimensions of the muffler are varied keeping some dimensions constant and then the effect on Backpressure is observed. It can be seen that the backpressure varies nonlinearly and it cannot be predicted by any equation. It can be concluded that the backpressure value is high for small diameters as compare to bigger diameter holes even if the porosity is doubled. But for higher diameters the Backpressure value remains the same even when the porosity is doubled. Varying the porosity of the muffler has pronounced effect on the backpressure. The change in diameter of holes has remarkable effect. There is sharp change in backpressure values even if hole diameter is slightly changed. There was a sudden decrease in backpressure values as porosity was increased[5].

Özdemir, et al. (2013) have analyzed the muffler by changing the length of each expansion chambers to understand the effects to the flow characteristics of a cross-flowed perforated and 3-expansion-chambered reactive muffler. It is known that an increase in the total muffler axial length results in a better noise attenuation performance. However, due to the reason of need of a muffler with lower volume for cost reduction, the effect of a cut on length of the muffler is examined. It is observed that $30 \%$ reduction on length of rear chamber did not make any difference on acoustic characteristics with base muffler model. To generate cross flow, inlet and outlet pipe's perforated part stand in the middle chamber. A decrease at the length of middle chamber prevents the cross flow. Thus, a greater pressure loss occur at this model[6].

\section{MUFFLER DESIGN}

Generally an exhaust muffler is required to satisfy some basic requirements such as adequate insertion loss, low back pressure, muffler sizing which could affect the cost and durability to withstand with rough use 
and extremely high temperatures[7]. So some design considerations should be taken for an optimal muffler design[8].

$>$ Mufflers with the extended tube chambers are better than those with simple chambers.

$>$ There is no significant difference between the insertion loss of a muffler with extended tube and that of a muffler with flow reversal chambers.

$>$ The greater the no. of chambers (with corresponding the increase in corresponding length), the better the insertion loss.

$>$ Within the same overall length of the shell, an increase in the number of chambers generally increases the insertion loss at higher frequencies but decreases it at lower frequencies.

$>$ The larger the area ratio of the chambers, the greater would be the insertion loss.

In order to select a suitable muffler type, some basic information are necessary regarding muffler as per the ASHRAE Technical Committee 2.6 [9]:

\section{Muffler grads:}

Industrial/Commercial:
$\mathrm{IL}=15$ to $25 \mathrm{dBA}$
Body/Pipe $=2$ to 2.5
Length/Pipe $=5$ to 6.5
Residential Grade:
$\mathrm{IL}=20$ to $30 \mathrm{dBA}$
Body/Pipe $=2$ to 2.5
Length/Pipe $=6$ to 10
Critical Grade:
$\mathrm{IL}=25$ to $35 \mathrm{dBA}$
Super Critical Grade:
$\mathrm{IL}=35$ to $45 \mathrm{dBA}$
Body/Pipe $=3$
Length/Pipe $=8$ to 10
Body/Pipe $=3$
Length/Pipe $=10$ to 16

$\mathrm{IL}=$ Insertion Loss, i.e., the level of sound reduction after attaching the muffler.

The proposed muffler is assumed to the critical grade and the mixed type of absorptive and reactive muffler with 3 chambers and tunable resonator. The chamber is perforated and wrapped with the glass wool for absorption.

\section{A. Initial Design Data:}

Max. Engine speed

No. of cylinders $(\mathrm{k})$

Inlet pipe diameter $\mathrm{d}$

$$
\begin{aligned}
& =5000 \mathrm{RPM} \\
& =3 \\
& =47 \mathrm{~mm}
\end{aligned}
$$

Maximum Temperature at inlet of muffler $=352^{\circ} \mathrm{C}$

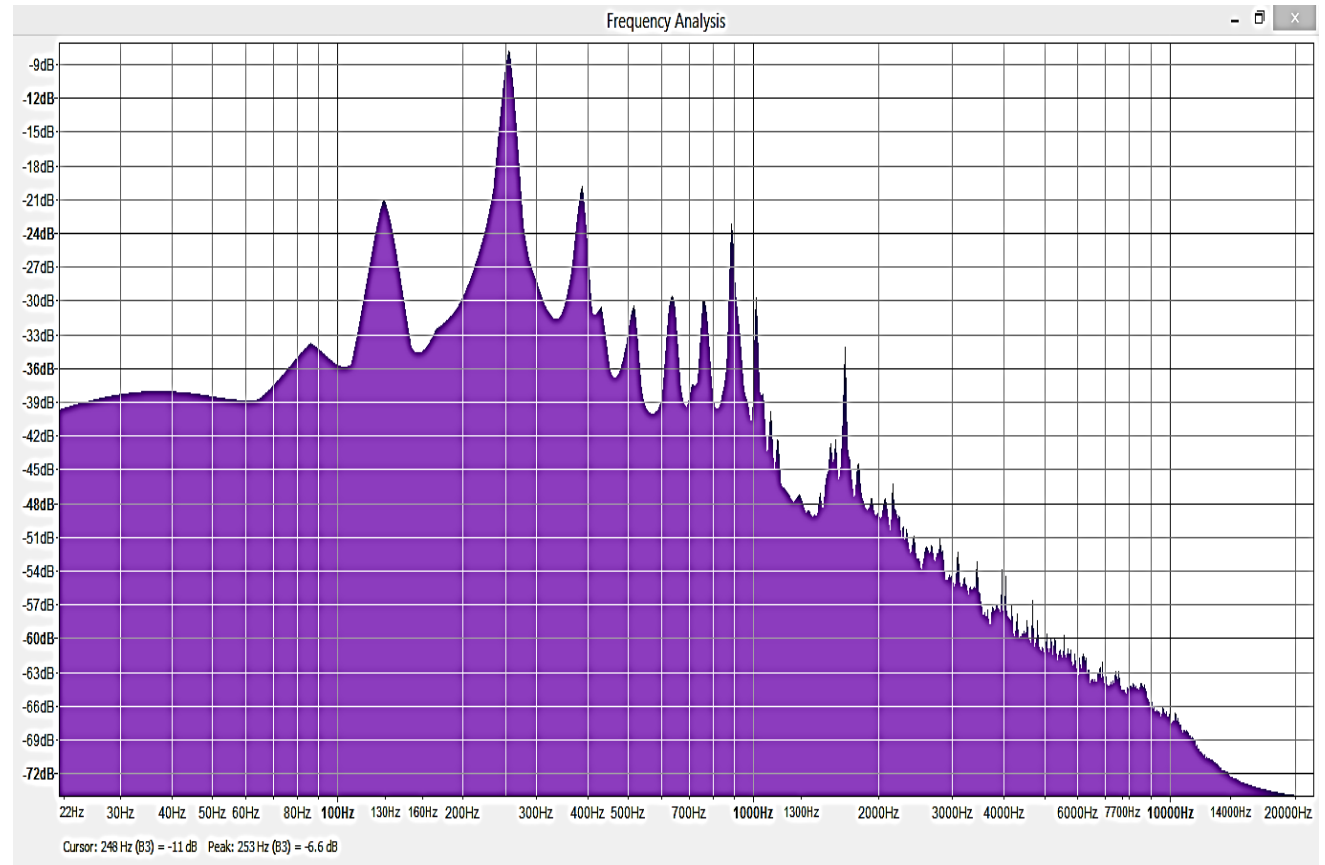

Figure 3 Sound level vs. Frequency graph

Experimental peak low level frequencies are found from the Figure 3 at $125 \mathrm{~Hz}, 253 \mathrm{~Hz}, 381 \mathrm{~Hz}, 509 \mathrm{~Hz}, 635$ $\mathrm{Hz}, 758 \mathrm{~Hz}$ and $882 \mathrm{~Hz}$.

\section{B. Chamber Design:}

1. Chamber length and diameter according to ASHRAE Technical Committee 2.6

According to ASHRAE Technical Committee 2.6, muffler grades and their dimensions, the requirement matches with the critical grade[9]. 
$\mathrm{IL}=25$ to $35 \mathrm{dBA}$, Body $/$ Pipe $=3$, Length/Pipe $=8$ to 10

Length of muffler chamber is $\mathrm{L}=8 * 0.047 \mathrm{~m}$ to $10 * 0.047 \mathrm{~m}$

$\mathrm{L}=0.376 \mathrm{~m}$ to $0.470 \mathrm{~m}$

Chamber diameter is $\mathrm{D}_{1}=3 * \mathrm{~d}=3 * 0.047 \mathrm{~m}=0.141 \mathrm{~m}$

Chamber diameter is taken as $0.141 \mathrm{~m}$.

\section{Resonance Method}

Maximum attenuation occurs when $\mathrm{L}=\mathrm{n} \lambda / 4 \ldots$ (1)

Where, $\lambda$ is the wavelength of sound $(m)$. And $n=1,3,5 \ldots$ (Odd integers)[10]. But for economical consideration we take $n=1$. And the reference value of speed of sound $V_{s}$ is taken as $330 \mathrm{~m} / \mathrm{s}$. The length is calculated for frequencies $381 \mathrm{~Hz}, 509 \mathrm{~Hz}, 635 \mathrm{~Hz}$ (other frequencies are either very short or very long chamber length) so that the length of the chamber is satisfy Ist method:

The wavelength $\lambda$ is calculated for different frequencies:

Wavelength $\lambda_{1}$ for frequency $381 \mathrm{~Hz}=\mathrm{V}_{\mathrm{s}} / \mathrm{f}_{3}=330 / 381=0.86 \mathrm{~m}$

Wavelength $\lambda_{2}$ for frequency $509 \mathrm{~Hz}=\mathrm{V}_{\mathrm{s}} / \mathrm{f}_{4}=330 / 509=0.65 \mathrm{~m}$

Wavelength $\lambda_{3}$ for frequency $635 \mathrm{~Hz}=\mathrm{V}_{\mathrm{s}} / \mathrm{f}_{5}=330 / 635=0.52 \mathrm{~m}$

So, the length of chamber according to these wavelength is given below:

Length of chamber for wavelength $\lambda_{1}=\lambda_{1} / 4=0.86 / 4=0.21 \mathrm{~m}$

Length of chamber for wavelength $\lambda_{2}=\lambda_{2} / 4=0.65 / 4=0.16 \mathrm{~m}$

Length of chamber for wavelength $\lambda_{3}=\lambda_{3} / 4=0.52 / 4=0.13 \mathrm{~m}$

We choose the length of chambers are $0.21 \mathrm{~m}$ for Ist chamber and IInd \& IIIrd Chamber are $0.16 \mathrm{~m}$ long, so the total length of chamber is taken as $0.21+0.13+0.13=0.47 \mathrm{~m}$ according to this method.

Dimensions of chamber is given as:

Diameter of chamber $\mathrm{D}_{1}=141 \mathrm{~mm}$

Total length of chamber $\mathrm{L}_{\mathrm{c}}=470 \mathrm{~mm}$

Length of Ist chamber

$=210 \mathrm{~mm}$

Length of IInd chamber

$=130 \mathrm{~mm}$

Length of IIIrd chamber

$=130 \mathrm{~mm}$

Diameter of perforated holes

$=3 \mathrm{~mm}$

\section{Baffle Pipes Design:}

Diameter of pipes inside the baffles are so that the cross section area doesn't reduce. So the Area of inlet pipe $=$ Total area of baffle pipe

2 pipes for the baffle are considered. So the diameter $\mathrm{d}_{1}$ is calculated as:

$\begin{array}{llll}\pi / 4 * \mathrm{~d}^{2} & = & 2 *\left(\pi / 4 * \mathrm{~d}_{1}{ }^{2}\right) & \\ \pi / 4 * 47^{2} & = & 2 *\left(\pi / 4 * \mathrm{~d}_{1}{ }^{2}\right) & \\ \mathrm{d}_{1} & = & 33.23 \mathrm{~mm}= & 35 \mathrm{~mm}\end{array}$

D. Absorptive material:

The glass wool is used for absorption and the thickness is $4 \mathrm{~mm}$.

E. Resonator

Resonators are used to attenuate low frequency noise. The principle is to create an opposite phase waveform to nullify each other. The simplest way to produce a wave of opposite phase is to put a reflective obstacle at a distance of $n \lambda / 4$, where $n=1,3 \ldots$ other odd integers. A value of $n=1$ has been used in the design. And the frequency range is taken from $250 \mathrm{~Hz}$ to $500 \mathrm{~Hz}$.

So the wavelength $\lambda$ corresponding to frequency $250 \mathrm{~Hz}=\mathrm{V}_{\mathrm{s}} / \mathrm{f}=1.32 \mathrm{~m}$

And the wavelength $\lambda$ corresponding to frequency $500 \mathrm{~Hz}=\mathrm{V}_{\mathrm{s}} / \mathrm{f}=0.66 \mathrm{~m}$

Maximum length of resonator cylinder $\mathrm{L}_{\mathrm{r} \max }=\lambda / 4=0.33 \mathrm{~m}$

Minimum length of resonator cylinder $\mathrm{L}_{\mathrm{r} \min }=\lambda / 4=0.165 \mathrm{~m}$

Length of tuning of resonator $\mathrm{L}_{\mathrm{rt}}=\mathrm{Lr}_{\max }-\mathrm{L}_{\mathrm{r} \min }=0.165 \mathrm{~m}$

Stopper pipe inlet diameter $=25 \mathrm{~mm}$

Stopper pipe outlet diameter $\quad=\quad 47 \mathrm{~mm}$

Length of stopper pipe $\quad=\quad 60 \mathrm{~mm}$

F. Resonator Rod

Diameter of resonator rod $\mathrm{d}_{\mathrm{rr}}=25 \mathrm{~mm}$

Length of resonator rod $\mathrm{L}_{\mathrm{rr}}=\mathrm{L}_{\mathrm{rt}}+$ Handle allowance + Stopper allowance $=0.165+0.025+0.060$

$$
=0.250 \mathrm{~m}
$$




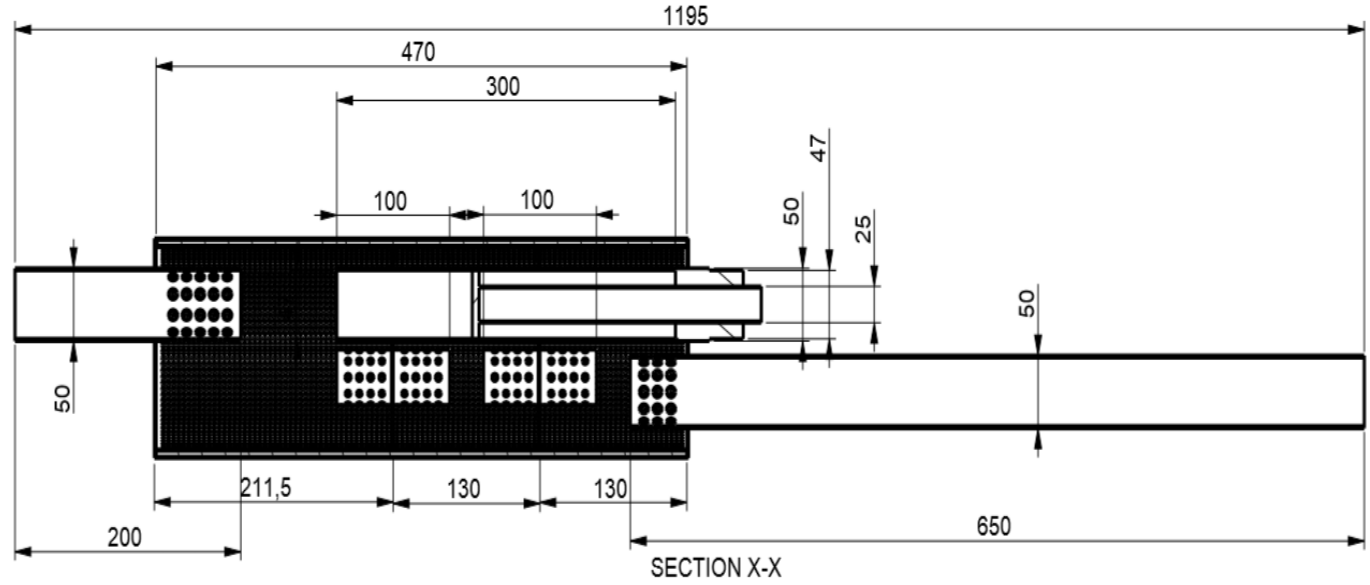

Figure 4 Cut section view of Silencer

Silencer is fabricated by stainless steel (SS-304). The fabricated silencer is shown in the Figure 5.

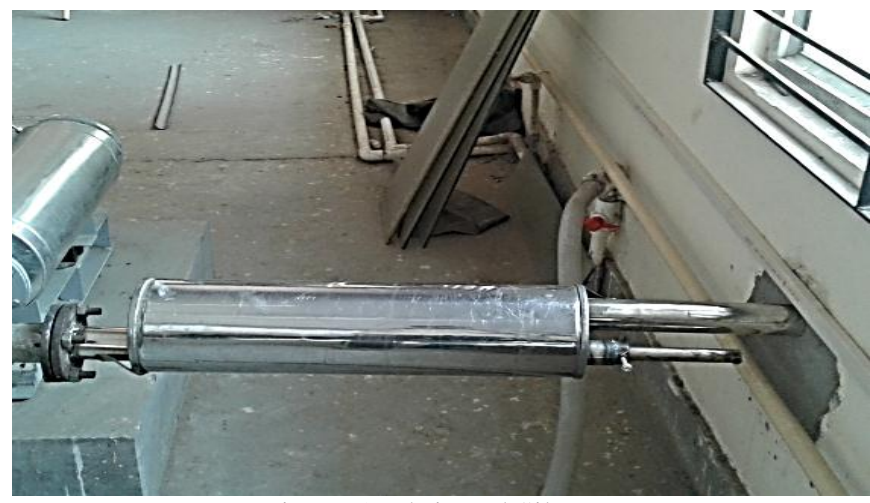

Figure 5 Fabricated Silencer

\section{RESULTS AND DiscUSSION}

Sound level is measured before and after the muffler installed at different speed. And the insertion loss is calculated when the resonator is extreme inside position because the sound level is recorded minimum at almost all engine speed. And also the sound level is measured from minimum to maximum piston displacement to check the effect of variation of length that is shown in the Figure 6.

Table 1 Insertion Loss at different Engine Speed

\begin{tabular}{|c|c|c|c|c|}
\hline \multirow{2}{*}{ S. No. } & \multirow{2}{*}{$\begin{array}{c}\text { Engine speed } \\
\text { (RPM) }\end{array}$} & \multicolumn{2}{|c|}{ Sound Level (dBA) } & \multirow{2}{*}{ Insertion Loss } \\
\cline { 3 - 4 } & & Before Muffler & After Muffler & \\
\hline 1 & 2000 & 90.1 & 76.1 & 14.0 \\
\hline 2 & 2500 & 91.5 & 80.1 & 11.4 \\
\hline 3 & 3000 & 93.9 & 83.8 & 10.1 \\
\hline 4 & 3500 & 96.1 & 85.9 & 10.2 \\
\hline 5 & 4000 & 97.9 & 87.8 & 10.1 \\
\hline 6 & 4500 & 100.0 & 88.9 & 11.2 \\
\hline 7 & 5000 & 106.5 & 90.1 & 16.5 \\
\hline
\end{tabular}


The maximum insertion loss of muffler is $16.5 \mathrm{dBA}$ and minimum insertion loss is $10.1 \mathrm{dBA}$. And the effect of length of resonator is shown in the Figure 6. It is clear from the graph that there is a small difference in the sound level that varies from 0 to maximum $2.9 \mathrm{dBA}$ when the resonator piston is displaced from the inside position (at which the size of resonator is small) to outside (at which the size of resonator is large). The difference in sound level at outside and middle position of resonator piston is smaller than the middle position to

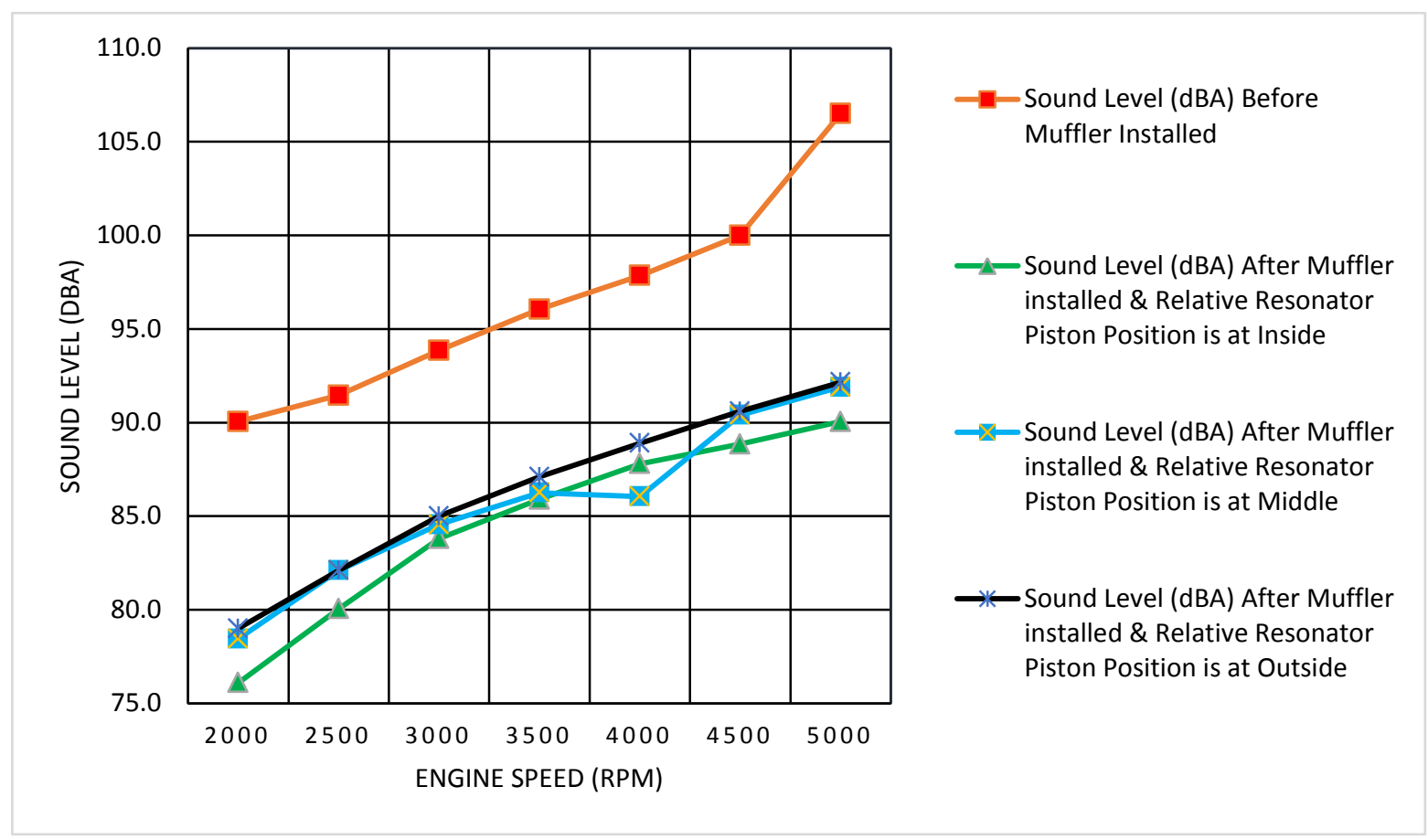

Figure 6 Variation of Noise at different position of resonator piston with speed

inside position. This shows that reduction in sound level is more as the size of resonator is reduced. There is an exception at $4000 \mathrm{rpm}$, at this speed the middle position of resonator piston gives better attenuation.

\section{CONCLUSION}

The designed muffler is used a tunable resonator which is resembles to a cylinder piston arrangement. The length of the resonator can be varied by pulling the piston rod and can be set any position at which the noise reduction is maximum by tightening the screw. The advantages of this resonator is that it is fitted along the line of muffler and directly after the inlet pipe so that it can cancel the noise of higher altitude as they enter the muffler. But the cost of this type of resonator is more due to piston and cylinder arrangement, so the tunable resonator is not economical for general purpose. The insertion loss is maximum $16.5 \mathrm{dBA}$. The maximum sound level after muffler installation is $90.1 \mathrm{dBA}$ as the position of resonator piston is extreme inside. The designed muffler is capable to attenuate high as well as low frequency noise. The resonator attenuate low frequency noise which lies between $250 \mathrm{~Hz}$ to $500 \mathrm{~Hz}$. The noise reduction is more at the resonator piston is at extreme inside position. The small size resonator attenuates more sound, smaller resonator is economical.

\section{ACKNOWLEDGMENT}

The work is done at Department of Mechanical Engineering, Inderprastha Engineering College, Ghaziabad, India.

\section{References}

[1] N. S. Chavan and D. S. B. Wadkar, "Design and Performance Measurement of Compressor Exhaust Silencer By CFD," International Journal of Scientific Research, ISSN No 2277 - 8179, vol. 2, no. 9, pp. 156-158, 2013.

[2] Potente and Daniel, "General Design Principles for an Automotive Muffler," in Australian Acoustical Society, Busselton, Western Australia, 2005

[3] T. D. Whitehead, "The Design of Resonant Absorbers," University of Canterbury, Christchurch, New Zealand, 2005.

[4] B. B. Ghosh, P. Bhattacharya, R. Panua and P. K. Bose, "Prediction of Noise Level by Mathematical Modeling in the Exhaust Muffler and Validation of these Analytical Results with the Experimental Results for 4-Stroke Diesel Engine," Advances in Applied Mathematical Analysis, ISSN 0973-5313, vol. Volume 2, pp. 41-47, 2007.

[5] S. D. Pangavhane, A. B. Ubale, V. A. Tandon and D. R. Pangavhane, "Experimental and CFD Analysis of a Perforated Inner Pipe Muffler for the Prediction of Backpressure," International Journal of Engineering and Technology, ISSN : 0975-4024, vol. 5, pp. 3940-3950, 2013. 
[6] E. Özdemir, R. Yılmaz, Z. Parlar and Ş. Arı, "An Analysis of Geometric Parameters' Effects on Flow Characteristic of a Reactive Muffler," in International Research/Expert Conference "Trends in the Development of Machinery and Associated Technology", Istanbul, Turkey, 2013.

[7] A. Mohiuddin, M. R. Ideres and S. M. Hashim, "Experimental Analysis of Noise and Back Pressure of Muffler Design," Jurnal Kejuruteraan, vol. 20, pp. 151-161, 2008.

[8] M. Munjal, A. Sreenath and M. Narasimhan, "An Algebric Algorithm for Design and Analysis of Linear Dynamical Systems," Journal of Sound and Vibration, vol. 26, no. 2, pp. 193-208, 1973.

[9] L. Bell, Industrial Noise Control, New York: Marcel Dekker, 1982.

[10] M. Rahman, T. Sharmin, A. F. M. E. Hassan and M. A. Nur, "Design and Construction of a Muffler for Engine Exhaust Noise Reduction," in International Conference on Mechanical Engineering, Dhaka, 2005. 